\title{
Breast Reconstruction after Surgical Treatment of Ductal Carcinoma In Situ
}

\author{
Manuela Bottoni, Alessandra Gottardi*, Mario Rietjens \\ Division of Plastic and Reconstructive Surgery, European Institute of Oncology, Milan, Italy
}

*Corresponding author:

Alessandra Gottardi, MD

Division of Plastic and

Reconstructive Surgery, European

Institute of Oncology, Milan, Italy

E-Mail: alessandra.gottardi@ieo.it

\section{Rezumat}

Rolul chirurgului plastician în reconstrucția sânilor este obligatoriu în acele cazuri de carcinom ductal in situ (DCIS) care necesită o excizie chirurgicală largă. Tratamentul reconstructiv trebuie adaptat fiecărui pacient cu scopul de a obține un rezultat cosmetic bun din punct de vedere al formei şi simetriei, evitând complicațiile chirurgicale.

Cuvinte cheie: carcinom ductal in situ, reconstrucție mamară

\section{Abstract}

The role of plastic surgeon in breast reconstruction is mandatory in those cases of ductal carcinoma in situ (DCIS) requiring a wide surgical excision. The reconstructive treatment must be tailored on each patient with the aim to obtain a good cosmetic result in terms of form and symmetry, avoiding surgical complications.

Key words: ductal carcinoma in situ, breast reconstruction

\section{Introduction}

Surgical treatment of DCIS includes breast-conserving surgery and mastectomy (Fig. 1). Breast reconstruction can be offered to almost all women undergoing oncological breast surgery. It allows to obtain better aesthetic results, and consequently a reduction of the psychological impact of oncological surgery, at 


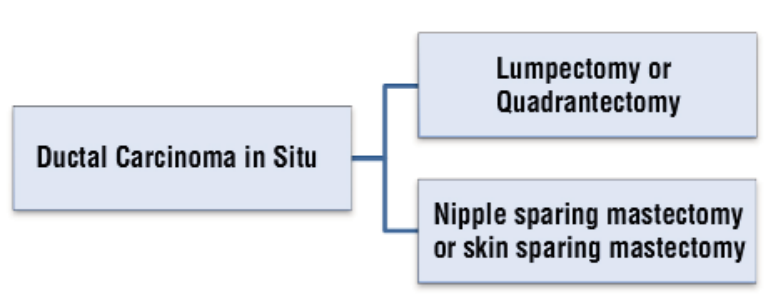

Figure 1. Oncological surgical treatment of DCIS

the price of a significant increase in complexity and surgical time and of the needs of a multidisciplinary team. However, breast reconstruction must not interfere with surgical and therapeutic oncological principles (1).

We suggest a decision algorithm for the reconstructive treatment of DCIS based on current international guidelines and our experience in the Division of Plastic and Reconstructive Surgery of European Institute of Oncology in Milan (Italy) (1).

\section{Breast Reconstruction after Conservative Surgery}

Conservative surgery and breast irradiation represent the main treatment of DCIS. The conservative surgical treatment must be chosen considering tumor size and localization, multifocality, characteristic of the breast and clinical evaluation of the patient (Fig. 2) (2).

\section{No reconstruction}

In all cases of hypoplasia, the tumor size and the glandular ptosis must be considered for the correct surgical choice. Only if the tumor size is smaller than $1 \mathrm{~cm}$, the residual breast after excision is sufficient to minimize the defect and the patient wants to preserve her breast, a conservative surgery can be indicated. In those cases where reconstructive surgery is not required, a delayed lipofilling can be useful to cover minimal defect obtaining a better

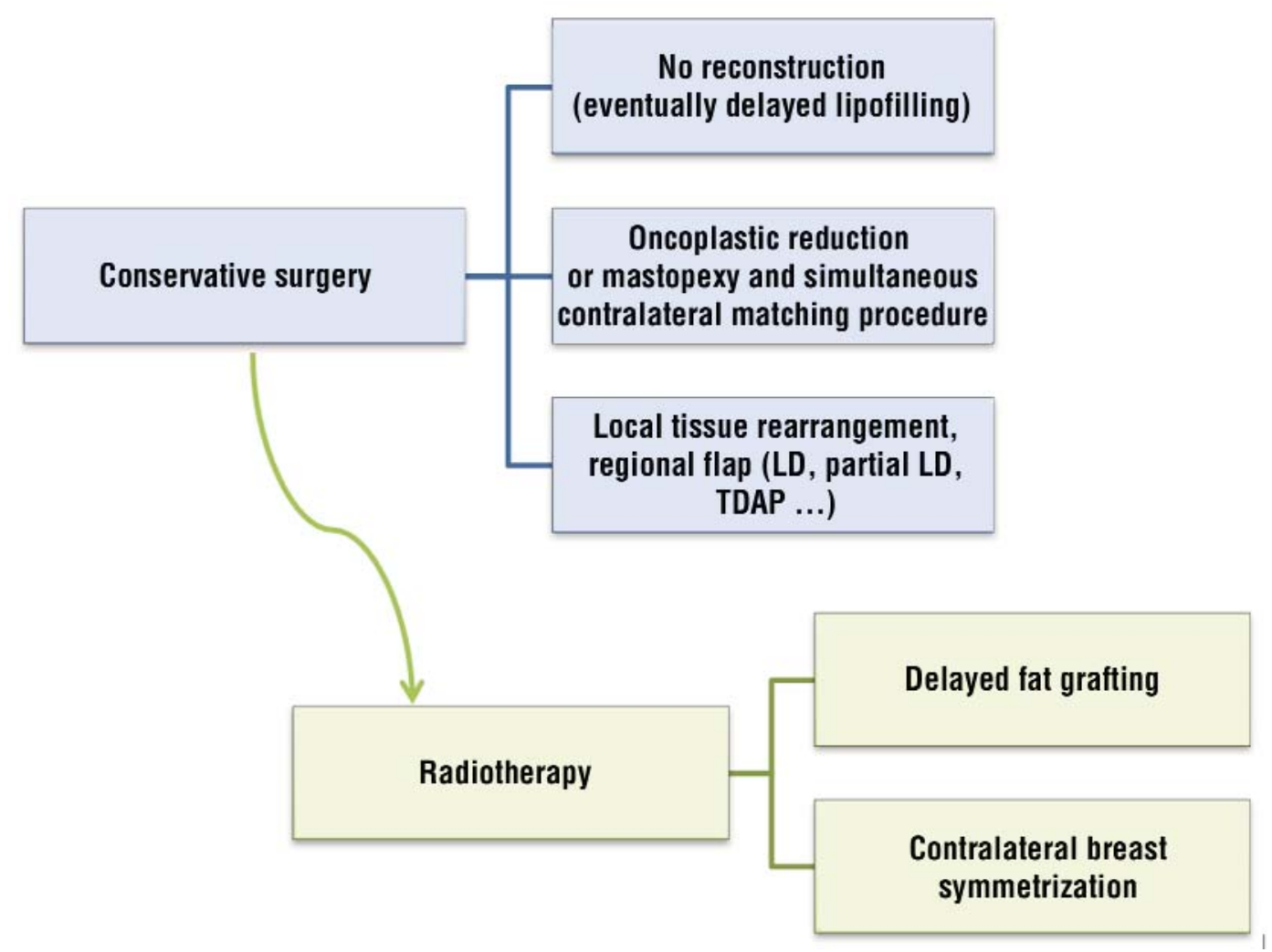

Figure 2. Flow chart representing the various reconstructive options in the case of conservative surgical treatment (NCCN Guidelines, version 4.2021, Invasive Breast Cancer, modified) 
symmetry with the contralateral breast. In small breasts, when the tumor size is greater than $1 \mathrm{~cm}$ and it is close to the skin, aesthetic result could not be satisfactory. In these cases, skin-sparing or nipple-sparing mastectomies must be considered to have a better reconstructive result (3).

\section{Oncoplastic reconstruction}

Lumpectomy or quadrantectomy could be indicated in cases of medium/high-volume breasts when an adequate free margins excision of the lesion can be obtained with sufficient breast conservation. The indications for conservative surgery could be extended by using oncoplastic surgery that combines wider demolition with immediate breast remodeling (4). It is demonstrated that oncoplastic surgery is a valid treatment option for the management of DCIS also in terms of oncological safety (5).

The Oncoplastic Surgery Committee (OSC), a committee formed by the American Society of Breast Surgeons (ASBrS), defines "oncoplastic surgery" as a "breast conservation surgery incorporating an oncologic partial mastectomy with ipsilateral defect repair, using volume displacement or volume replacement techniques, with contralateral symmetry surgery as appropriate". The committee also defines a classification system in levels based on the volume of the breast removed. Level 1 is defined by a volume displacement (volume of the breast used for closing the defect of the lumpectomy and redistributing the preserved breast) lower of the $20 \%$ of the whole breast. When the volume displacement is between $20 \%$ and $50 \%$ of the whole breast the surgery is classified as Level 2 (6).

Oncoplastic surgery includes a series of reconstructive techniques useful to restore shape, integrity, and symmetry to the breasts after oncological removal. Contraindications to oncoplastic surgery can be extensive tumor, especially if located in the medial region, lowvolume and no ptosis breast, history of breast irradiation, diabetes, tobacco addiction and collagen diseases (3).

The tumor position is the most important factor to consider in preoperative planning. In case of small excision in upper quadrants of the breast, local glandular flaps can be immediately used to completely cover the defect. Inferior pedicle techniques similar to those proposed by Ribeiro and Robbins can be applied in wider upper quadrant excisions $(7,8)$. Different techniques are described to cover central quadrant resections: a purse string with local glandular flaps can be used in breasts without ptosis; in case of ptosis, Grisotti's flap can cover the defect and simulate a new nipple areola complex by moving a cutaneous-glandular flap from the inferior quadrant $(9,10)$. Superior pedicle techniques as those described by Pitanguy and Lejour in breast reduction can be used in cases of central or inferior defects of high-volume breasts (11-13). Contralateral breast reduction is necessary in all cases of wide excisions or important ptosis corrections to obtain a greater breast's symmetry (Fig. 3).

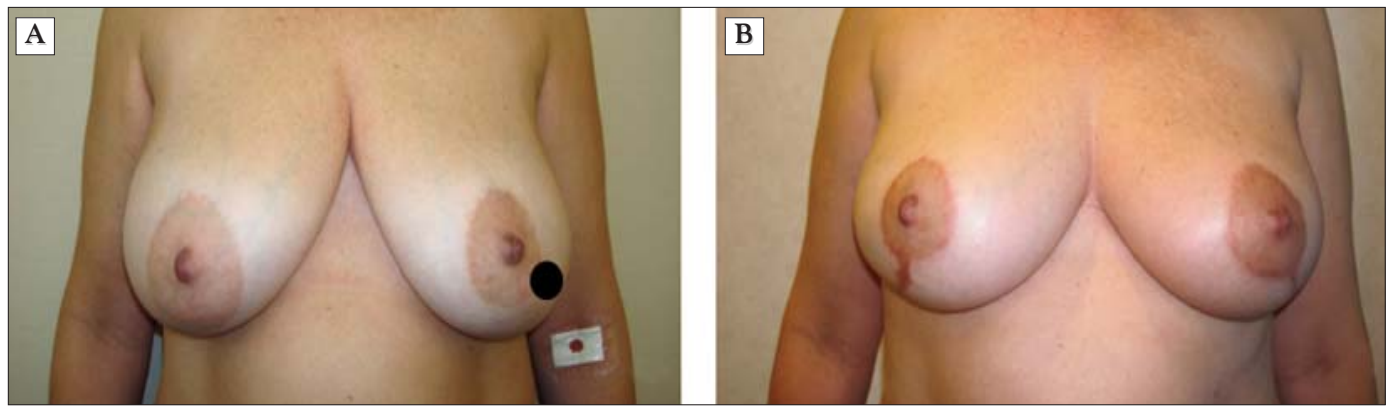

Figure 3. (A) Preoperative aspect of a patient with diagnosis of DCIS of the inferior external quadrant of the left breast (black point). The patient underwent left breast infero-lateral quadrantectomy and remodeling and right breast reduction mammoplasty. (B) Postoperative aspect at 6 months after radiotherapy of the left breast 


\section{Regional flap}

In those cases of wide excision of the skin, especially in atypical positions, or when the patient refuses a breast reduction, volume replacement techniques can be used. Chatterjee et al. add volume replacement to OSC's definition to classify all situations when elsewhere tissue is recruited to cover the breast defect (> 50\% of breast tissue removed) (6).

Conventional flaps used in those situations are thoraco-epigastric flaps, thoraco-lateral flaps, bilobed flaps or thoracodorsal flaps. In the last decade the use of these flaps has been reduced in favor of more conservative flaps based on perforating arteries. The defects of the lower part of the breast can be replaced by using local flaps such as abdominal adipofascial flaps or thoraco-epigastric perforator flaps (TAP) (14-18). Lateral intercostal artery perforator flap (LICAP), lateral thoracic artery perforator flap (LTAP) and thoracodorsal artery perforator flap (TDAP) can be used to cover the defects of the lateral half of the breast (19-23).

\section{Adjuvant Radiotherapy (RT)}

Breast-conserving surgery is often associated with adjuvant radiotherapy in order to reduce ipsilateral recurrence of local or invasive events. The effects of radiotherapy can lead to changes in the breast contour and symmetry and require further surgical corrections. Delayed fat grafting can be used to correct long-term residual deformities of the irradiated breast. In case of asymmetry, the contralateral breast can be subjected to mastopexy or reduction mammoplasty (24).

\section{Breast reconstruction after mastectomy}

As already described, the surgical treatment of DCIS of the breast includes a variety of patient and tumor factors. A breast conservative surgery must be excluded in case of multicentric disease, staged T4 disease, large tumor in small breast or when breast irradiation is contraindicated (Fig. 4).

Mastectomy could be the only surgical indication in women with small breasts in which

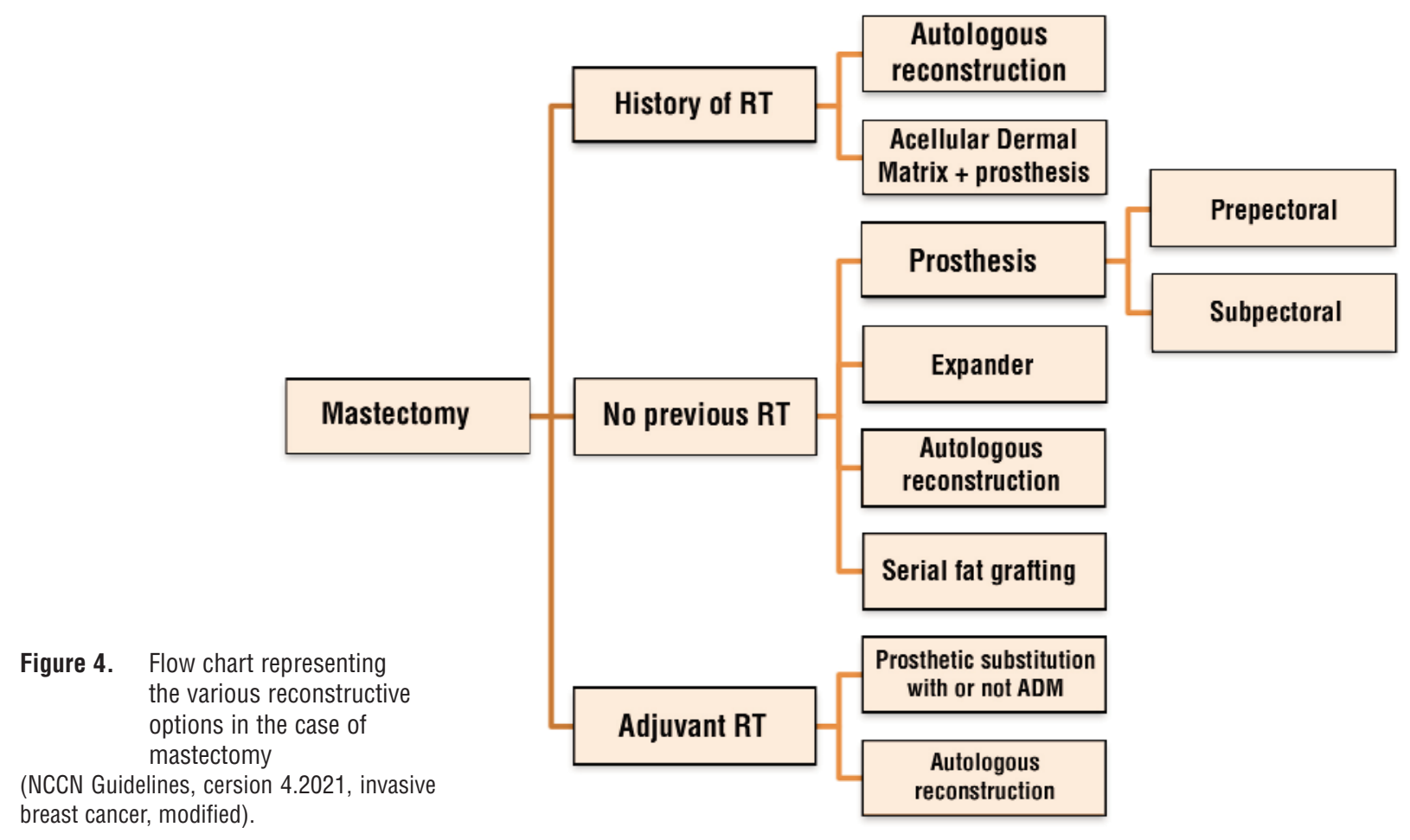


an adequate resection could involves an unacceptable cosmetic result.

Nipple-sparing mastectomy is considerate a natural evolution of a skin sparing mastectomy where the removal of all glandular tissue is associated with the conservation of nippleareola complex. This technique can be obviously used in case of ascertained absence of nipple disease. The surgical technique has improved in the last decades and it allows to maximize the cosmetic result being oncologically safe (25).

\section{No previous $R T$}

Implant breast reconstruction is the most conservative option for patients who supposedly do not require radiotherapy after surgery. Implant based reconstruction can occur both in a single stage and in two stages.

When the local conditions of the surgical site after mastectomy allow it, the single stage reconstruction with the placement of a permanent implant is the best reconstructive choice. Otherwise, when after mastectomy there are not ideal tissue conditions (for example skin flaps are too thin, the amount of breast skin removed is too extensive, etc.) is mandatory to perform two stages reconstruction, with the primary implant of a tissue expander.

When the patient is not a candidate for implant breast reconstruction due to her body type, because of the presence of previous breast scar or in the cases in which the patient refuses implant, the use of autologous flaps can be a valid alternative (26).

Furthermore, the reconstructive technique of lipofilling can be used for breast reconstruction in patients who are not candidate for major surgery or in women who want to avoid the use of implants.

Breast reconstruction with fat grafting has been widely described. Selection criteria for breast reconstruction with fat tissue are primarily: adequate donor site, small to moderate-sized breast and, not less important, patient's motivation to undergo several surgery sessions. In fact, autologous reconstruction with adipose tissue requires more surgical interventions due to the need to implant a not excessive amount of fat and the unpredictability of its postoperative resorption.

Fat grafting can be also used in combined technique with an implant. With this composite approach, after a first intervention of positioning of a tissue expander, the patient undergoes serial surgical procedures of progressive expander deflation and lipofilling sessions. In the final surgical session, the expander can be completely replaced by the adipose tissue or replaced with a smaller volume implant.

The main benefit of this matched procedure is a more natural and pleasant aesthetic outcome (27).

\section{Prepectoral implant reconstruction}

The traditional techniques in prosthetic breast reconstruction indicates partial or total coverage of the prosthetic devices. Despite the efficacy and safety of this technique, implant placement under the pectoralis major muscle often involves muscle contractions and spasms that can cause chronic pain or cosmetic changes that may not be well tolerated by all patients. In selected cases, it can be possible to implant the prosthetic device in the subcutaneous plane reducing these local postoperative issues.

Furthermore, this surgical technique is surgically easier, and it allows to reduce the anesthetic times. Despite the considerable advantages, the technique is not free from complications, therefore a correct patient selection is necessary. BMI $>40$, diabetes mellitus, immunocompromising of the patient, prior radiation therapy, the presence of large tumors involving the skin and muscle, or active tobacco use, represent major contraindications factor to this technique. Moreover, implant needs an adequate soft-tissue support, therefore oncological resection has to preserve the vascularity skin flaps leaving the normal subcutaneous fat layer intact, thus the indications for pre-pectoral implant breast reconstruction includes moderately-sized breasts with a thick well-vascularized mastectomy flap (Fig. 5) (28).

If the thickness of the mastectomy flap or skin vascularity is poor, the risks of delayed 


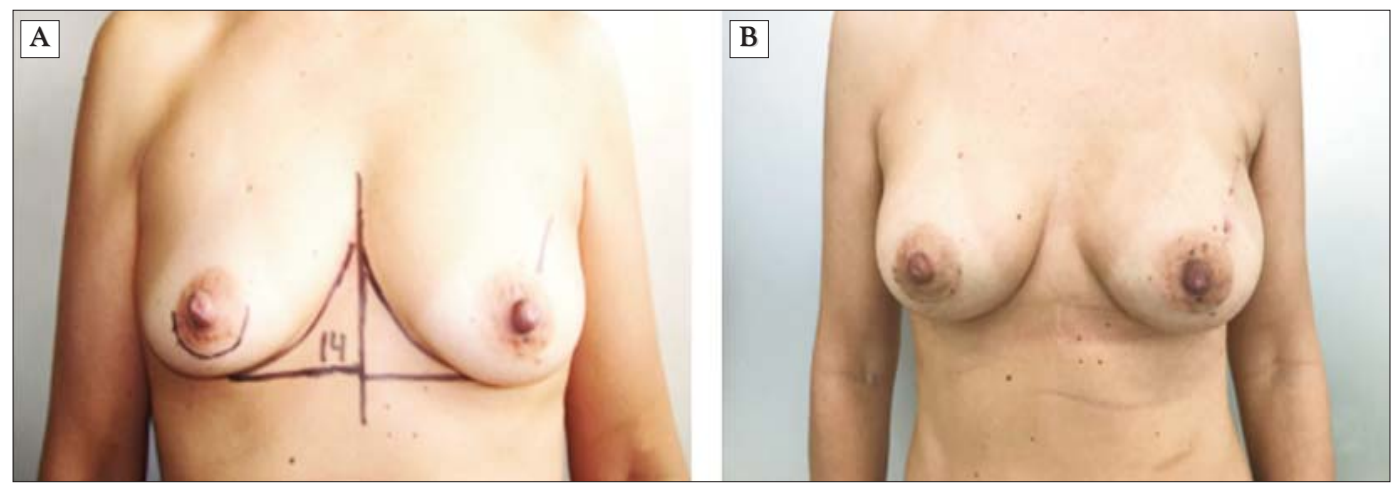

Figure 5. (A) Preoperative aspect of a patient with diagnosis of DCIS of the left breast. The patient underwent left mastectomy and reconstruction with prepectoral prosthesis and meshed acellular dermal matrix on the inferior pole and contralateral subglandular breast augmentation. The patient has not been subjected to any postoperative therapies. (B) Postoperative aspect at 6 months.

healing and skin necrosis are greater. Late healing can interfere with the timing of adjuvant therapies by delaying them. In these cases, it is preferable to adopt the subpectoral technique.

\section{History of radiotherapy}

Breast reconstruction in previously irradiated patients must consider the higher complication rate due to the side effects of radiotherapy on the soft tissue. The choice of the type of reconstruction (heterologous or autologous) and the timing (immediate or delayed) depends on various variables such as the patient's comorbidities, the stage of the tumor, the need for adjuvant therapies, the body type, the size and shape of the breast, personal preferences and wishes of the patient. All these aspects must be considered when choosing the technique and planning the correct surgical procedure (29). Autologous flaps (pedicled or free flaps) represent the gold standard for patients with history of previous radiotherapy.

Autologous reconstruction provides excellent and long-lasting results in terms of shape, texture, sensitivity, and integrity of the body image.

Different flaps can be used for breast reconstruction. Latissimus dorsi (LD) flap (Fig. 6), transverse rectus abdominis myocutaneous (TRAM) flap (Fig. 7), deep inferior epigastric perforator (DIEP) flap, transverse upper gracillis (TUG) flap, thigh flaps and gluteal flaps are the most used.

\section{Acellular dermal matrix (ADM)}

A new option for breast reconstruction in patients with history of irradiation of the chest wall is the use of a biological matrix as a support of the muscular pocket for the implant.

Acellular dermal matrices (ADMs) are laboratory products derived from fetal bovine, porcine or human cadaver and represent scaffolds that are re-inhabited by autologous cells in the months after their implantation $(30,31)$.

The ADM can be used sutured to the lower edge of the pectoralis major during the creation of the submuscular pocket for the implant, providing the inferior coverage of the prosthesis and preserving the inframammary fold (Fig. 8).

In selected cases, the use of ADM to cover the implant can provide a good aesthetic result without increasing the complication rate in the irradiated breast. Also, this technique requires a meticulous choice of the patient's suitability in order to avoid postoperative complications. The most important factors necessary in the indication of this type of reconstruction are represented by breasts of small volume (cup A or B), a good quality of the mastectomy flaps and the absence of skin radio-dystrophy.

\section{Adjuvant radiotherapy}

The best type of breast reconstruction for women who have undergone mastectomy and 

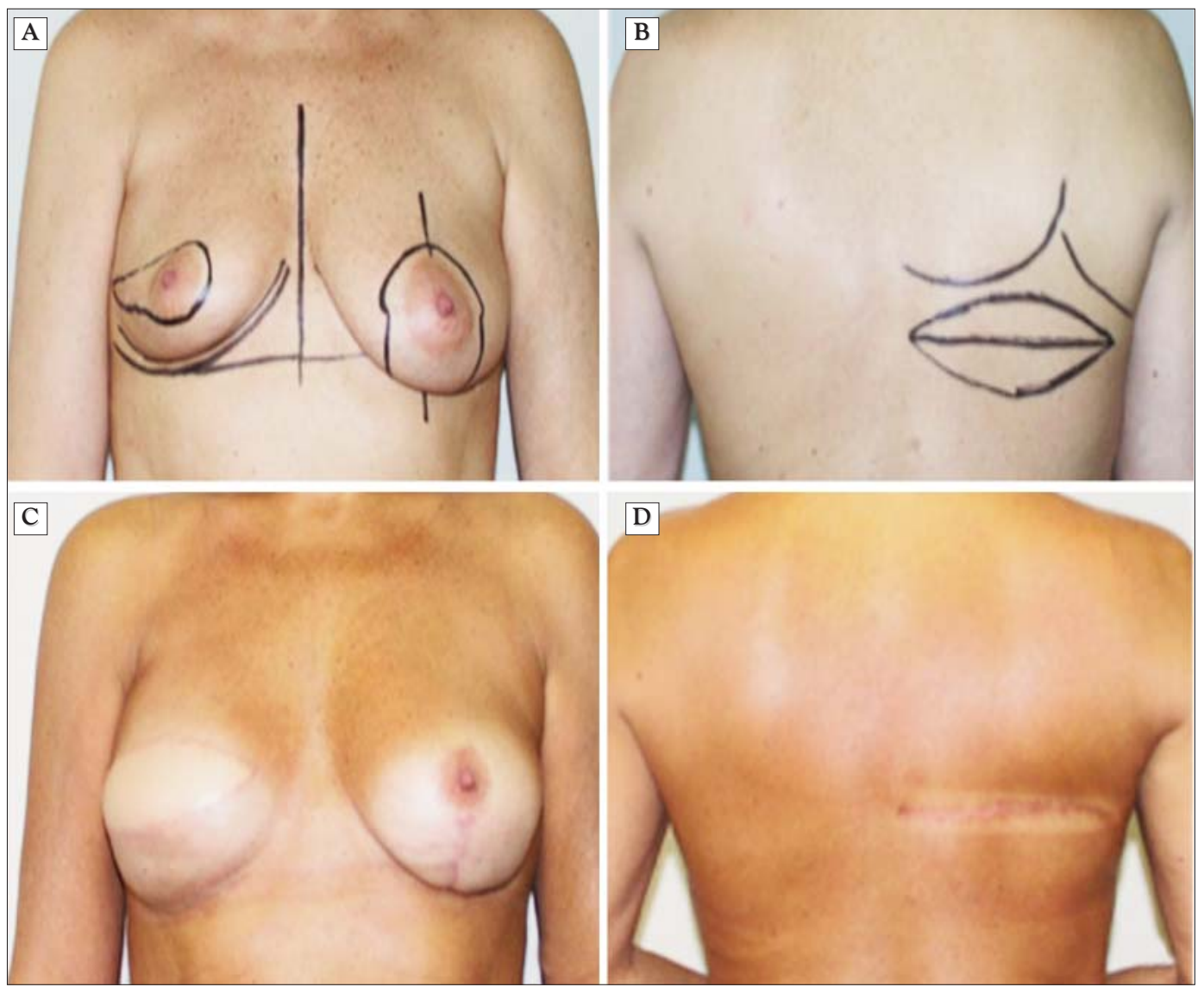

Figure 6. (A) Preoperative planning of right mastectomy and contralateral mastopexy in patient with DCIS of the right breast. (B) Preoperative planning of the cutaneous paddle of latissimus dorsi flap. The horizontal orientation of the excision allows to hide the scar with a bra. (C) Frontal postoperative photo 6 months after surgery. D. Dorsal postoperative photo at 6 months.

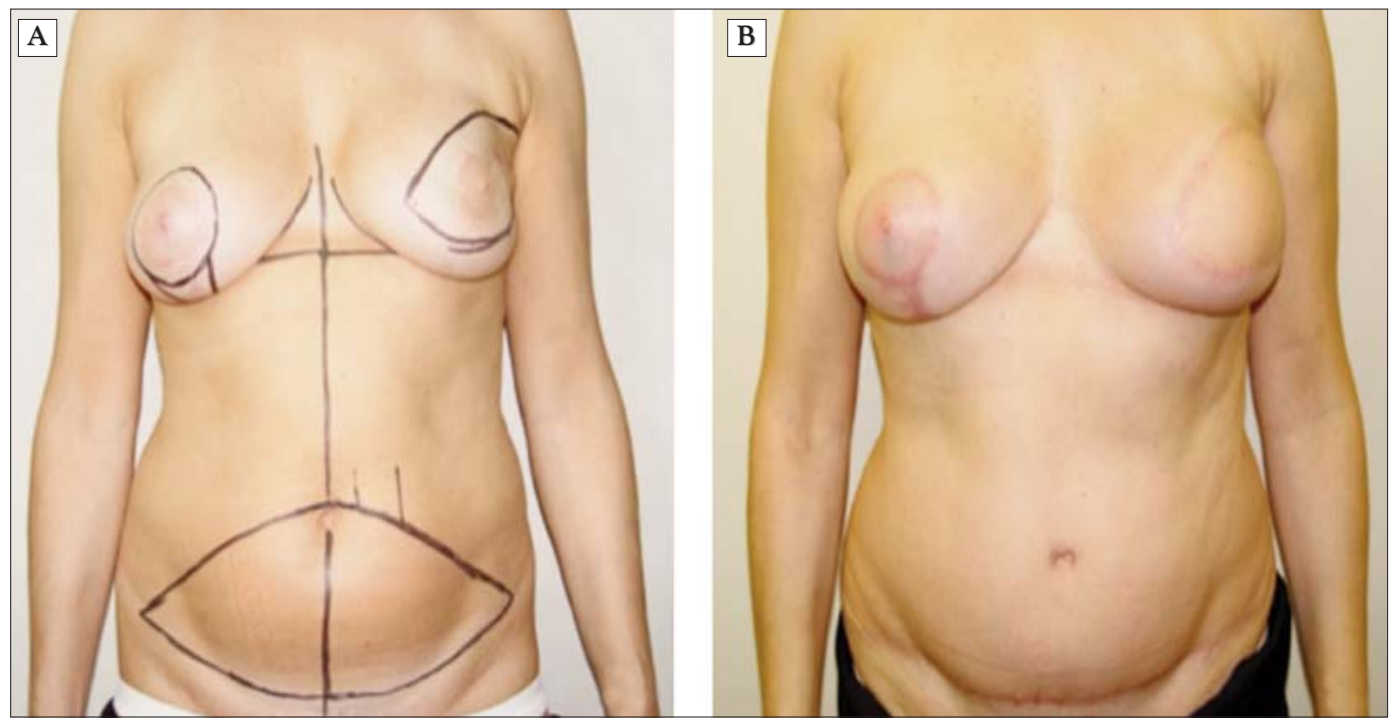

Figure 7. (A) Patient with left breast recurrence of DCIS after mastectomy, reconstruction with prosthesis and right mastopexy. Preoperative planning of wide excision of skin and nipple areola complex of the left breast, reconstruction with transverse rectus abdominis myocutaneous flap and second right mastopexy. (B) Postoperative aspect 6 months after surgery. 

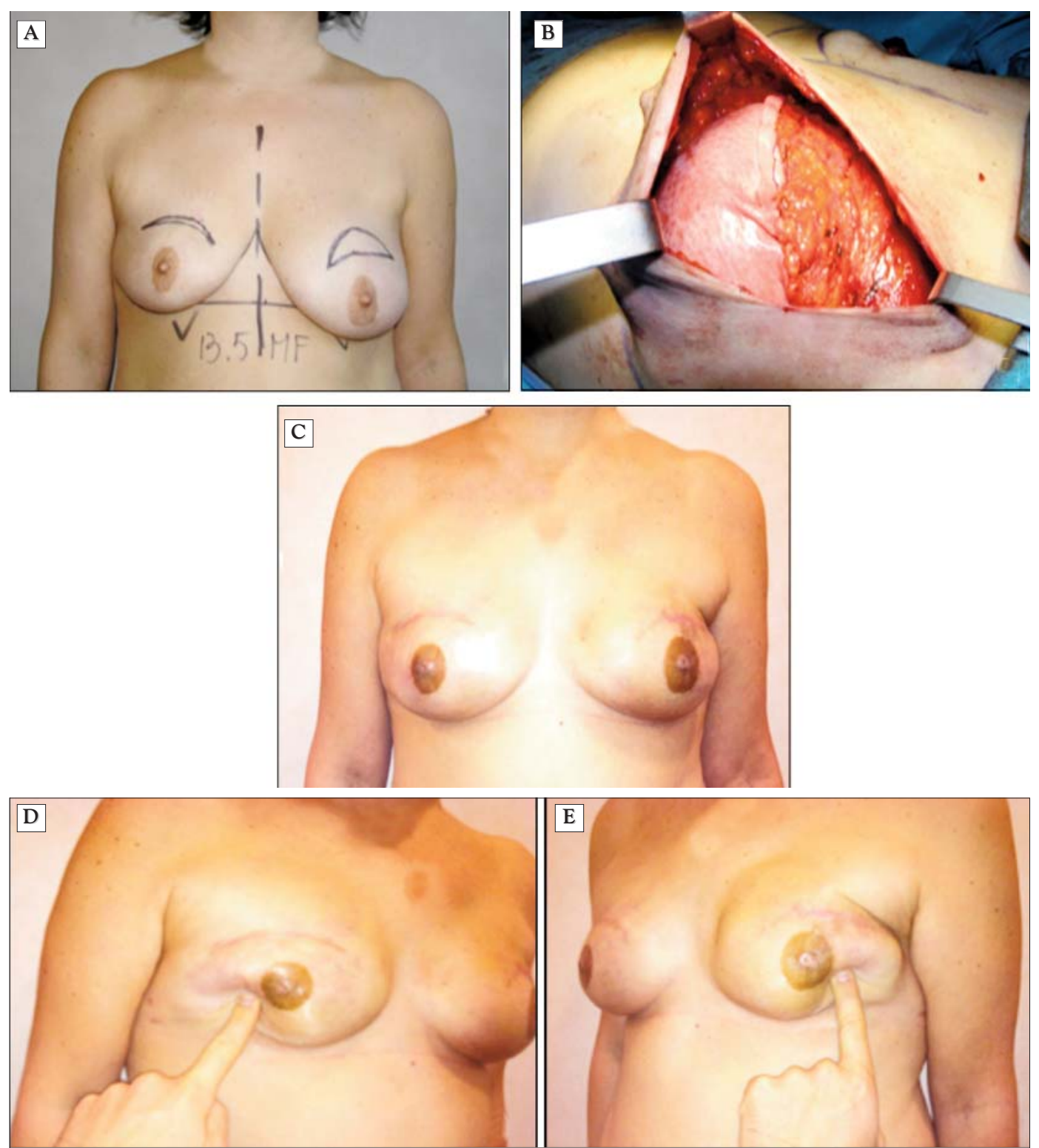

Figure 8. (A) Preoperative planning of bilateral mastectomy in patient with previous quadrantectomy and radiotherapy of the right breast. (B) Intraoperative reconstruction: the prosthetic pocket is constituted by the pectoralis major muscle (upper part) and an acellular dermal matrix of bovine pericardium (lower part). (C) Postoperative result 6 months after surgery. (D) No sign of capsular contraction at the left breast.

need adjuvant radiotherapy is still controversial (32). Also, in this case the goal should be to minimize side effects and reduce the frequency of immediate or delayed complications due to radiotherapy without compromising the aesthetic result. The open questions mainly concern the timing of the reconstruction (immediate versus delayed), the type of reconstruction (implants versus autologous) and the radiotherapy technique (conventional or unconventional).
Depending on radiotherapy technique, dose, fraction and target volume, new evidence show that autologous reconstruction can improve quality of life and cosmetic results compared with traditional implant reconstruction (32-33).

\section{Conflict of Interest}

The authors declare they have no conflict of interest. 


\section{Ethics Approval}

The authors obtained the consent of the patients for the publication of their photos.

\section{References}

1. National Comprehensive Cancer Network. Breast Cancer Guidelines 4.2021. Invasive Breast Cancer. 2021; 51-7.

2. Van la Parra RFD, Nos C, Sarfati I, Clough KB. Improving Breast Cancer Surgery: A Classification and Quadrant-per-Quadrant Atlas for Oncoplastic Surgery. In: Urban C, Rietjens M, El-Tamer M, Sacchini V editors. Oncoplastic and Reconstructive Breast Surgery. Second Edition. Cham: Springer. 2019. p. 285-306.

3. Urban C, Lima R, Schunemann E, Spautz C, Rabinovich I, Anselmi K. Oncoplastic principles in breast conserving surgery. Breast. 2011;20 Suppl 3:S92-5.

4. Morrow M, Van Zee KJ, Solin LJ, Houssami N, Chavez-MacGregor M, Harris JR, et al. Society of Surgical Oncology-American Society for Radiation Oncology-American. Society of Clinical Oncology Consensus Guideline on Margins for Breast-Conserving Surgery With Whole-Breast Irradiation in Ductal Carcinoma in Situ. Pract Radiat Oncol. 2016;6(5): 287-295.

5. De Lorenzi F, Di Bella J, Maisonneuve P, Rotmensz N, Corso G, Orecchia R, et al. Oncoplastic breast surgery for the management of ductal carcinoma in situ (DCIS): is it oncologically safe? A retrospective cohort analysis. Eur J Surg Oncol. 2018;44(7):957-962

6. Chatterjee A, Gass J, Patel K, Holmes D, Kopkash K, Peiris L, et al. A Consensus Definition and Classification System of Oncoplastic Surgery Developed by the American Society of Breast Surgeons. Ann Surg Oncol. 2019;26(11):3436-3444.

7. Ribeiro L, Accorsi Jr A, Buss A, Marcal-Pessoa M. Creation and evolution of 30 years of the inferior pedicle in reduction mammaplasties. Plast Reconstr Surg. 2002;110(3):960-70.

8. Robbins TH. Reduction mammaplasty by the Robbins technique. Plast Reconstr Surg. 1987;79(2):308-9.

9. Huemer GM, Schrenk P, Moser F, Wagner E, Wayand W. Oncoplastic techniques allow breast-conserving treatment in centrally located breast cancers. Plast Reconstr Surg. 2007;120(2):390-398.

10. Galimberti V, Zurrida S, Zanini V, Callegari M, Veronesi P, Catania S, et al. Central small size breast cancer: how to overcome the problem of nipple and areola involvement. Eur J Cancer. 1993:29A(8):1093-6.

11. Petit JY, Garusi C, Greuse M, Rietiens M, Youssef 0 , Luini A et al. One hundred and eleven cases of breast conservation treatment with simultaneous reconstruction at the European Institute of Oncology (Milan). Tumori. 2002:88(1):41-7.

12. Lejour M. Vertical mammaplasty: update and appraisal of late results. Plast Reconstr Surg. 1999;104(3):771-81

13. Pitanguy I, Torres E, Salgado F, Pires Viana GA. Breast pathology and reduction mammaplasty. Plast Reconstr Surg. 2005;115(3):729-34.

14. Ogawa T, Hanamura N, Yamashita M, Ri Y, Kuriyama N, Isaji S, at al. Usefulness of breast-volume replacement using an inframammary adipo-fascial flap after breast-conservation therapy. Am J Surg. 2007:193(4):514-8.

15. Kijima Y, Yoshinaka H, Hirata M, Arima H, Nakajo A, Shinden Y, et al.
Oncoplastic surgery combining partial mastectomy and immediate volume replacement using a thoracodorsal adipofascial cutaneous flap with a crescent-shaped dermis. Surg Today. 2014;44(11):2098-105.

16. Kijima Y, Yoshinaka H, Hirata M, Mizoguchi T, Ishigami S, Arima H, et al. Immediate reconstruction using a modified thoracodorsal adipofascial cutaneous flap after partial mastectomy. Breast. 2011;20(5):464-7.

17. Takeda M, Ishida T, Ohnuki K, Suzuki A, Kiyohara H, Moriya T, et al. Breast conserving surgery with primary volume replacement using a lateral tissue flap. Breast Cancer. 2005;12(1):16-20.

18. Hamdi M, Craggs B, Stoel AM, Hendrickx B, Zeltzer A. Superior epigastric artery perforator flap: anatomy, clinical applications, and review of literature. J Reconstr Microsurg. 2014;30(7):475-82.

19. Hamdi B, Van Landuyt K, De Frene B, Roche N, Blondeel P, Monstrey S. The versatility of the inter-costal artery perforator (ICAP) flaps. J Plast Reconstr Aesthet Surg. 2006;59(6):644-52.

20. Munhoz AM, Montag E, Arruda E, Brasil JA, Aldrighi JM, Gemperli R, et al. Immediate conservative breast surgery reconstruction with perforator flaps: new challenges in the era of partial mastectomy reconstruction? Breast. 2011;20(3):233-40.

21. Uppal RS, Stillaert FB, Hamdi M. Antiphospholipid syndrome - a rare cause of free flap thrombosis in perforator flap breast reconstruction. J Plast Reconstr Aesthet Surg. 2008;61(3):347-8.

22. McCulley SJ, Schaverien MV, Tan VKM, Macmillan RD. Lateral thoracic artery perforator (LTAP) flap in partial breast reconstruction. J Plast Reconstr Aesthet Surg. 2015;68(5):686-91.

23. Roy PG. One-stage vs. two-stage approach for partial breast reconstruction with lateral chest wall perforator flaps. Cancer Treat Res Commun, 2016; 9:56-61.

24. Petit JY, Maisonneuve P, Rotmensz N, Bertolini F, Clough KB, Sarfati I, et al. Safety of Lipofilling in Patients with Breast Cancer. Clin Plast Surg. 2015; 42(3):339-44.

25. Galimberti V, Vicini E, Corso G, Morigi C, Fontana S, Sacchini V, et al. Nipple-sparing and skin-sparing mastectomy: Review of aims, oncological safety and contraindications. Breast. 2017;34 Suppl 1(Suppl 1):S82-S84.

26. Toyserkani NM, Jørgensen MG, Tabatabaeifar S, Damsgaard T, Sørensen JA. Autologous versus implant-based breast reconstruction: A systematic review and meta-analysis of Breast-Q patient-reported outcomes. J Plast Reconstr Aesthet Surg. 2020;73(2):278-285.

27. Sommeling CE, Van Landuyt $K$, Depypere $H$, Van den Broecke R, Monstrey S. Blondeel PN, et al. Composite breast reconstruction: Implant-based breast reconstruction with adjunctive lipofilling. J Plast Reconstr Aesthet Surg. 2017:70(8):1051-1058.

28. Ter Louw RP, Nahabedian MY. Prepectoral Breast Reconstruction. Plast Reconstr Surg. 2017 Nov;140(5S Advances in Breast Reconstruction): 51S-59S.

29. Ho AY, Hu ZI, Mehrara BJ, Wilkins EG. Radiotherapy in the setting of breast reconstruction: types, techniques, and timing. Lancet Oncol. 2017;18(12): e742-e753.

30. Kim MJ, Ahn SJ, Fan KL, Song SY, Lew DH, Lee DW. Inlay graft of acellular dermal matrix to prevent incisional dehiscence after radiotherapy in prosthetic breast reconstruction. Arch Plast Surg. 2019;46(6):544-549.

31. Cuomo R. Submuscular and Pre-Pectoral ADM Assisted Immediate Breast Reconstruction: A Literature Review. Medicina (Kaunas). 2020;56(6):256.

32. Ho TB, Wood WC, Mspt PDS. Breast Reconstruction in the Setting of Postmastectomy Radiotherapy: Controversies and Disparities. Oncology (Williston Park). 2019;33(12):688845.

33. Yun JH, Diaz R, Orman AG. Breast Reconstruction and Radiation Therapy. Cancer Control. 2018;25(1):1073274818795489. 